\title{
De novo subgaleal abscess
}

\author{
JP SCHAEFER, BSC(HON), LJ CLEIN, MB, FRCSC, JM CONLY, MD, CCFP, FRCPC, FACP
}

JP Schaefer, LJ Clein, JM Conly. De novo subgaleal abscess. Can J Infect Dis 1992;3(1):30-32. The authors report a case of spontaneous subgaleal abscess formation in a 62-year-old woman without antecedent trauma or injury. She presented with occipital scalp pain and swelling which rapidly became generalized two days following recovery from an upper respiratory infection. Diagnosis was based on radiological examination and aspiration of the subgaleal space, which yielded a purulent exudate with a pure growth of Streptococcus pyogenes. Initial management with incision, drainage and parenteral antimicrobial therapy was not successful. Operative exploration of the subgaleal space revealed extensive necrosis of the galea aponeurotica, and bone curettings revealed microscopic evidence compatible with osteomyelitis. Management with debridement and excision of all necrotic tissue plus prolonged parenteral antimicrobials was successful. Subgaleal abscess formation without an overlying wound or previous trauma has not been reported previously.

Key Words: Abscess, Aponeurosis, Spontaneous, Subgaleal

\section{Abcès développé de novo sous la galéa}

RESUME: Les auteurs rapportent le cas d'un abcès qui s'est développé spontanément sous la galéa chez une femme âgée de 62 ans qui n'avait subi ni traumatisme ni lésion. Le symptôme initial était une douleur occipitale du cuir chevelu et l'oedème s'est rapidement généralisé deux jours après que la patiente s'est remise d'une infection des voies respiratoires supérieures. Le diagnostic s'appuyait sur un examen radiologique et l'aspiration de l'espace atteint, dont on a extrait un exsudat purulent; les bactéries isolées comportaient uniquement Streptococcus pyogenes. Le traitement initial - incision, drainage et antibiothérapie par voie parentérale - a échoué. L'exploration chirurgicale de l'espace intéressé a mis en évidence une nécrose êtendue de l'aponévrose épicrânienne et le curetage de l'os a révélé des aspects microscopiques compatibles avec l'ostéomyélite. Le débridement et l'excision de tous les tissus nécrotiques suivis d'un traitement antimicrobien parentéral prolongé ont abouti. La formation d'un abcès de ce type en l'absence de plaie ou de traumatisme antérieur n'avait pas encore été rapportée.

Section of Infectious Diseases, Department of Medicine and Division of Neurosurgery, Department of Surgery, University of Saskatchewan, Saskatoon, Saskatchewan

Correspondence and reprints: Dr JM Conly. Section of Infectious Diseases, Department of Medicine, University of

Saskatchewan, Saskatoon, Saskatchewan S7N OXO. Telephone (306) 966-1777

Received for publication August 13, 1990. Accepted November 22, 1990 
$\mathrm{S}$ UBGALEAL ABSCESSES AND OSTEOMYELITIS OF THE SKULL are rarely encountered today (1). Recent reports of these entities usually describe an underlying pathology such as trauma or puncture wounds which account for direct inoculation or contiguous spread of microorganisms (2-11). Although the diagnosis and management of a secondary subgaleal abscess may be straightforward, the same cannot be said for a primary or de novo subgaleal abscess. The authors report a case of a patient who developed a de novo subgaleal abscess and secondary osteomyelitis.

\section{CASE PRESENTATION}

A 62-year-old female was referred to the neurosurgical service at University Hospital complaining of painful fluctuant swellings of the scalp. She had been well until six weeks prior to admission, when she experienced symptoms of an upper respiratory tract infection with dysphonia, mild fever and malaise, for which symptomatic relief was obtained with acetylsalicylic acid tablets. Two days after the upper respiratory infection had subsided, the patient noted pain of moderate intensity in the occipital area with radiation toward the frontal regions of the skull. Within days the entire scalp had become swollen and markedly painful. There was no history of antecedent thermal, chemical or mechanical trauma. Past medical history included hypertension controlled with thiazide diuretics and an appendectomy performed many years previously. There was no suggestion of sinusitis, diabetes or any immunological disorder. Other than swelling over the scalp and tenderness to palpation, examination was normal.

The patient was admitted to a local hospital, where skull radiographs and computed tomography scan revealed only soft tissue swelling over the calvarium. No evidence of mucosal thickening or opacification of the sinuses was apparent. Although the alkaline phosphatase level was elevated at $180 \mathrm{U} / \mathrm{L}$ (normal 30 to 85), a technetium bone scan did not reveal any evidence of osteomyelitis. An incision was made into the subgaleal space and $180 \mathrm{~mL}$ of purulent material was drained. A small drain was left in this incision for approximately one week. This exudate contained many Gram-positive cocci and pus cells, and culture revealed a pure growth of Streptococcus pyogenes. The patient was treated initially with parenteral cefazolin $1 \mathrm{~g}$ every $8 \mathrm{~h}$ for 21 days, and after some improvement was changed to oral cephalexin for a further seven days. However, the swelling did not resolve, and she was subsequently transferred to the authors' institution for further assessment.

Examination revealed three painful fluctuant swellings each measuring approximately $2 \mathrm{~cm}$ in diameter over the occipital, left parietal and frontal areas of the skull. Other physical findings included moderate alopecia and palpable posterior cervical lymph nodes. Ophthalmoscopy and otoscopy were unremarkable.
There was no meningismus. Complete neurological examination was unremarkable. A complete blood count revealed a hemoglobin of $103 \mathrm{~g} / \mathrm{L}$, a white blood cell count of $11.4 \times 10^{9} / \mathrm{L}$ (81\% neutrophils, 13\% lymphocytes and $6 \%$ monocytes), a packed cell volume of 0.31 , and an erythrocyte count of $3.2 \times 10^{9} / \mathrm{L}$. The erythrocyte sedimentation rate was $76 \mathrm{~mm} / \mathrm{h}$. The streptozyme (F Horner Inc) titre was 1:1000. A technetium bone scan indicated an area of increased uptake over the left parietal bone, suggesting a focus of osteomyelitis.

Treatment was started with intravenous penicillin G three million units every $4 \mathrm{~h}$, and the patient was taken to the operating room for incision and debridement. A sagittal incision about $15 \mathrm{~cm}$ in length was made and the subgaleal space widely explored. The galea aponeurotica was found to be extensively necrotic. All necrotic tissue was excised. Gross inspection revealed no apparent abnormalities of the bone. The wound was closed and two Penrose drains were brought out through separate stab incisions on each side. The drains were shortened and removed in five days. Microscopic examination of the bone curettings revealed numerous neutrophils with occasional intracellular Gram-positive cocci. Culture of the debrided material both aerobically and anaerobically revealed no growth.

Based on the clinical and laboratory findings, a diagnosis of subgaleal abscess and osteomyelitis of the parietal bone secondary to Strep pyogenes was made. The patient was treated with intravenous penicillin $\mathrm{G}$ for a total of six weeks, and has remained well after six months of follow-up.

\section{DISCUSSION}

Infections of the scalp may involve any of the tissue layers superficial to the calvarium (skin, subcutaneous tissue, aponeurosis, loose connective tissue or periosteum), and although most are minor and limited, they can progress to involve the deeper layers. Subgaleal abscesses are purulent infections deep to the galea aponeurotica (aponeurosis epicranialis) of the scalp. The subgaleal space, which is a potential anatomical space beneath the galea aponeurotica, extends from the supraorbital ridge anteriorly, to the cervical muscles posteriorly, and to the auricular muscles laterally. Loose connective tissue carrying emissary veins from the dural sinuses to the superficial scalp veins binds the galea to the periosteum of the skull.

Infections of the subgaleal space are uncommon, and the published series and case reports always describe an antecedent pathology which predisposes the patient to infection (2-11). Scalp trauma (2,3), plastic and reconstructive surgery $(4,5)$, contiguous septic focus (6), fetal scalp monitoring $(7,8)$, neoplasm (9) and hematoma (10) have been described in association with subgaleal abscesses. Once microorganisms gain access to the subgaleal space, the inflammatory process may spread with alarming rapidity through this enclosed 
space. Osteomyelitis of the calvarium, intracranial suppuration and necrosis of the scalp may complicate the original infection.

The de novo appearance of a subgaleal abscess has not been reported previously. On direct questioning, the present patient did not have any antecedent trauma or disruption of the scalp prior to infection, and there was no evidence of immunological compromise based on clinical examination and laboratory findings. The infection likely occurred due to hematogenous spread, related to the upper respiratory infection which occurred just prior to the onset of scalp swelling. The diagnosis of subgaleal abscess in the present patient was based mainly on clinical findings and aspiration and culture of exudate from the subgaleal space. Plain radiography, computed tomography and technetium99 methylene diphosphonate bone scanning were useful adjuncts in making an anatomical diagnosis. The bone scan suggested an underlying osteomyelitis which was subsequently confirmed upon microscopy. The course of the present patient's infection was monitored clinically and was uneventful. The failure to respond to initial treatment was likely due to inadequate debridement and drainage, the unrecognized presence of osteo-

ACKNOWLEDGEMENTS: The authors extend their thanks to Ms J Sklarchuk for typing this manuscript.

\section{REFERENCES}

1. Razzouk A, Collins N, Zirkle T. Chronic extensive necrotizing abscess of the scalp. Ann Plast Surg 1988:20:124-7.

2. Goodman SJ, Cahan L, Chow AW. Subgaleal abscess: A preventable complication of scalp trauma. West J Med 1977; 127:169-72.

3. Granick MS, Conklin W, Ramasastry S, Talamo TS. Devastating scalp infections. Am J Emerg Med 1986:4:136-40.

4. Geter RK. Puckett CL. Salvage of infected expanded scalp without loss of flap length. Plast Reconstr Surg 1987:80:720-5.

5. Jones JW, Ignelzi RJ, Frank DH, Blacklock JB. Osteomyelitis of the skull following scalp reduction and hair plug transplantation. Ann Plast Surg 1980:5:480-2. myelitis, and possibly the initial treatment with cefazolin rather than penicillin $\mathrm{G}$.

The predominant organism isolated from post traumatic and post surgical scalp infections is Staphylococcus aureus (11). However, other organisms such as Strep pyogenes (9) and Eikenella corrodens (5) have been reported. In the neonatal age group, in which abscess formation can be a complication of fetal scalp electrode monitoring, Staphylococcus epidermidis accounted for $58 \%$ of positive cultures in one review (8). Polymicrobial infections may also occur with the presence of anaerobes in association with either Staph aureus or Strep pyogenes (2).

The preferred surgical treatment of subgaleal abscess is incision, meticulous debridement and drainage $(1,2,11)$, although repeated needle aspirations may occasionally be successful (10). Purulent exudate or debrided tissue should be sent for immediate Gram smear and cultured both aerobically and anaerobically. Parenteral antimicrobial therapy is administered for one to three weeks, followed by appropriate oral therapy. Indwelling drains are often required. If a complication such as osteomyelitis is present, more prolonged therapy is required.

6. Akhtar MI, Chandler JR. Periorbital, subgaleal, and epidural empyema secondary to eikenella sinusitis. Ear Nose Throat J 1979;58:358-61.

7. Feder HM Jr, MacLean WC Jr, Moxon R. Scalp abscess secondary to fetal scalp electrode. J Pediatr 1976:89:808-9.

8. Plavidal FJ, Werch A. Fetal scalp abscess secondary to intrauterine monitoring. Am J Obstet Gynecol 1976; 125:65-70.

9. Robson MC, Zachary LS, Schmidt DR, et al. Reconstruction of large cranial defects in the presence of heavy radiation damage and infection utilizing tissue transferred by microvascular anastomoses. Plast Reconstr Surg 1989;83:438-42.

10. Wiley JF, Sugarman JM, Bell LM. Subgaleal abscess: An unusual presentation. Ann Emerg Med 1989;18:785-7.

11. Haines SI, Chou SN. Infections of the scalp and osteomyelitis of the skull. In: Wilkins RH, Rengachary SS, eds. Neurosurgery. Toronto: McGraw-Hill Book Co, 1985:1964-7. 


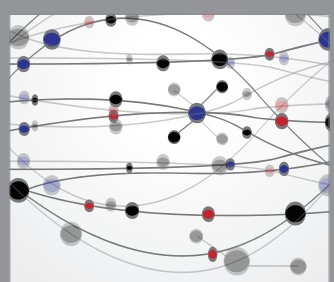

The Scientific World Journal
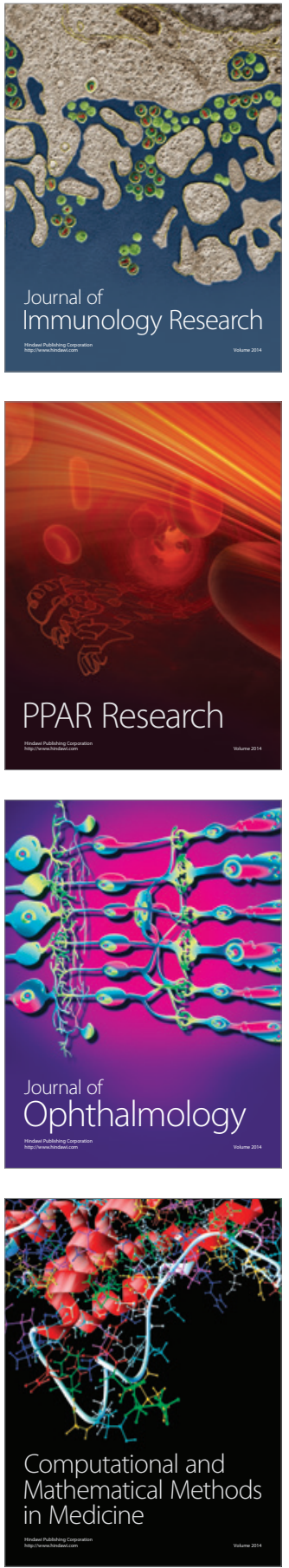

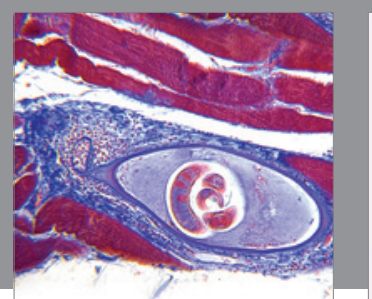

Gastroenterology Research and Practice

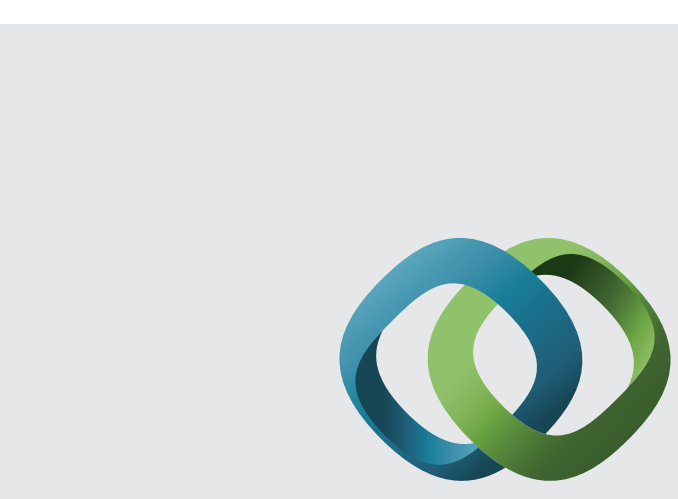

\section{Hindawi}

Submit your manuscripts at

http://www.hindawi.com
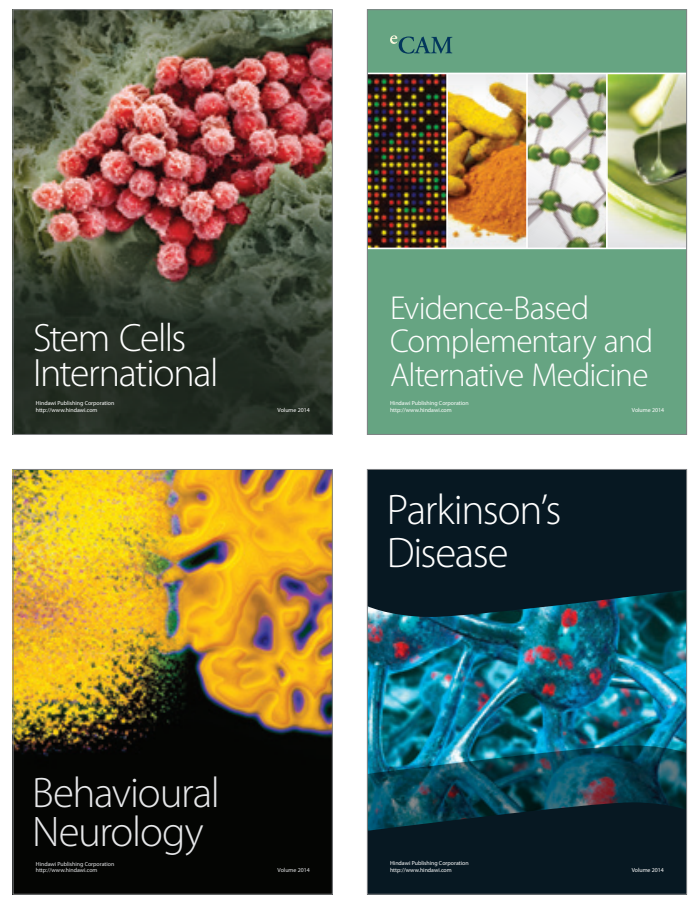
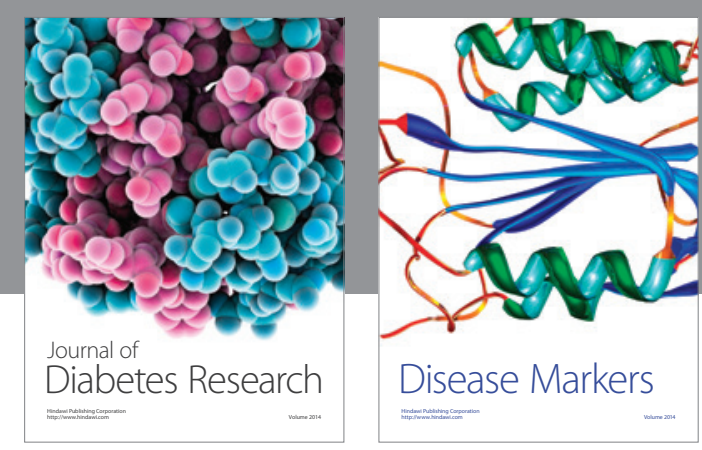

Disease Markers
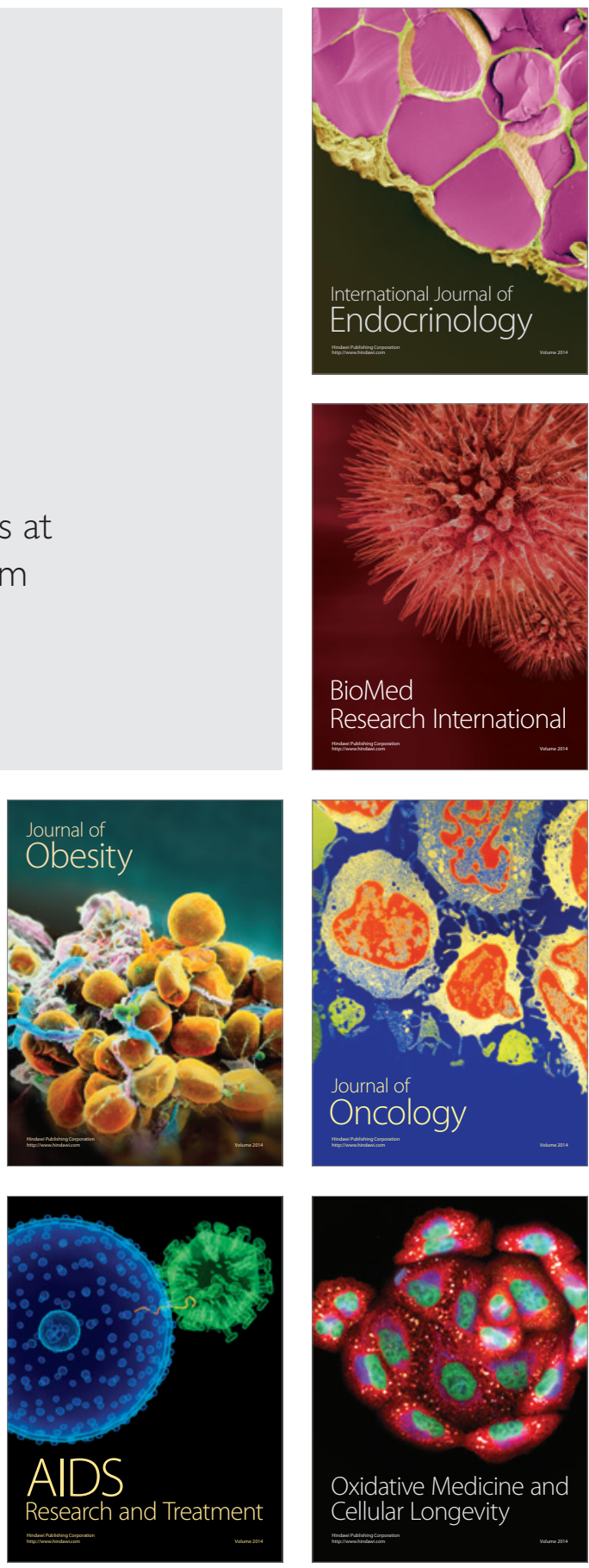